\title{
¿Hacia una civilización universal? Una crítica del «choque de civilizaciones» de Huntington
}

\author{
Manuel M. ${ }^{a}$ Urrutia León \\ Profesor de Sociología del Hecho Religioso \\ Universidad de Deusto
}

Recibido: 01.10 .08

Aceptado: 22.10.08

\begin{abstract}
Resumen: Desde su aparición en 1993, la teoría del «choque de civilizaciones» del politólogo Samuel P. Huntington se ha convertido en una de las más divulgadas y debatidas. En este artículo, tras una minuciosa lectura del libro de Huntington, se realiza una serie de críticas fundamentales a su paradigma para la política global: su concepción cerrada de las civilizaciones, su visión negativa de la diversidad cultural, su relativismo cultural, etc. Para concluir defendiendo un paradigma alternativo para las relaciones internacionales: el de un diálogo intercultural basado en el núcleo universalista de la democracia y los derechos humanos.

Palabras clave: Choque de civilizaciones. Diversidad cultural. Islam. Universalismo.

Abstract: From its appearance in 1993, the theory of the "clash of civilizations» of the political scientist Samuel P. Huntington has turned into one of the most spread and debated. In this article, after a meticulous reading of the book of Huntington, a series of fundamental critiques are presented to his paradigm for the global politics: his closed conception of the civilizations, his negative vision of the cultural diversity, his cultural relativism, etc. To end up by defending an alternative paradigm for the international relations: that of an intercultural dialogue based on the universal nucleus of the democracy and the human rights.
\end{abstract}

Key words: Clash of civilizations. Cultural diversity. Islam. Universalism.

Sumario: 1. Introducción.-2. Un nuevo paradigma en relaciones internacionales: el «choque de civilizaciones».-3. El desafío de la diversidad cultural.-4. ¿Una civilización universal?-5. Conclusión: ¿hacia dónde va la política global?-6. Bibliografía citada.

\section{Introducción}

Los sociólogos deben levantarse temprano y recorrer desde el amanecer el nuevo paisaje que han creado las perturbaciones de la noche. No pueden aplicar a unas realidades nuevas interpretaciones cuya extrema elaboración sólo había podido formarse tras una larga jornada de análisis y de reflexión. Su papel consiste ante todo en señalar discontinuidades, en no mirar hacia las luces del pasado sino más bien hacia la confusión de la realidad visible y formular la interrogación más inquietante: si las institu- 
ciones han perdido su capacidad de regulación y de integración, ¿qué fuerza puede acercar y combinar desde este momento una economía transnacional y unas identidades infranacionales? [...].

¿Cómo podemos vivir juntos?, es decir, ¿cómo podemos combinar la igualdad y la diversidad? (Touraine, 1997: 22 y 230).

Las palabras de Alain Touraine, escritas casi a la vez que el libro de Huntington, El choque de civilizaciones y la reconfiguración del orden mundial, son una buena introducción para el presente artículo. En esencia, la pretensión de las obras de ambos pensadores era muy similar, si bien ahí acaban las coincidencias y todo lo demás - planteamiento, desarrollo y conclusiones- son ciertamente diferentes. Nos encontramos, sugiere Touraine, en una nueva época, oscura, desconcertante. La manera en que la globalización va imponiéndose a lo largo del mundo ha resquebrajado hasta los cimientos mismos nuestras construcciones prolongadamente asentadas. La perplejidad es el signo de nuestro tiempo. No sólo se ha trastocado nuestra realidad, que aparece presidida por la confusión, sino que muchas de las categorías del pensamiento con las que nos acercábamos a ella, en nuestras ciencias humanas y sociales, se han vuelto inadecuadas. Necesitamos tiempo, que no tenemos, para renovarlas o aun para crearlas, si queremos incidir en una realidad que no espera a que estemos preparados. Y entre todos los interrogantes acuciantes que debemos plantearnos descuella uno, el que Touraine escribió en la portada de su libro, «¿Podremos vivir juntos?», al que acompañó con el par de conceptos y de realidades que hemos de tratar de conjugar si queremos que el mundo no se nos vaya, más aún, de las manos: «Iguales y diferentes».

Pues bien, como decía, creo que se puede leer muy bien la obra de Huntington a través del contrapunto establecido por la de Touraine. En efecto, Huntington trata de ofrecernos un nuevo paradigma para interpretar nuestra confusa realidad -que define a su manera-, pero mucho me temo que se le va la mano con lo «diferentes» que al parecer somos (las culturas, las civilizaciones), y olvida, o cuanto menos minimiza de forma preocupante, lo «iguales» que también somos (los humanos), con lo que obviamente el objetivo fundamental que se planteaba el sociólogo, qué hacer para poder convivir, apenas hace acto de presencia entre los varios cientos de páginas de la obra de Huntington dedicadas, casi en su totalidad, a anunciar un casi inevitable choque entre civilizaciones. Pero no nos adelantemos.

Estamos ante un libro famoso y, como suele ocurrir en estos casos, sobre todo si el texto es extenso, muchos presuntos críticos hablan de él sin haberlo leído cuidadosamente. Creo que el asunto del que trata es tan importante, que bien merece una lectura detenida. Sólo así las críticas que le podamos plantear cobrarán todo su sentido. Máxime cuando se trata de un libro extraño, no banal, aunque sí enormemente tajante en sus afirmaciones. Concuerdo plenamente con estas palabras de Martínez, referidas al artículo inicial de Huntington (1993), pero que muy bien pueden aplicarse igualmente a su libro posterior (1996): 
En el tema mismo, en los diversos capítulos a lo largo de los cuales el autor lo va exponiendo y analizando, Huntington es de una contundencia conceptual, léxica y sintáctica total, de un rigor innegable, tanto que podría ser entendido también como excesiva rigurosidad.

El suyo es un texto en el que no se atisba el mínimo resquicio por el que se cuele ni el interrogante ni la hipótesis, no hace la menor concesión, no ya a una incipiente dialéctica, sino ni tan siquiera al moderado contraste. Quizá esto les parezca a algunos una simple cuestión de estilo, de forma. Yo creo que es algo más: cuestión de fondo [...].

Sea lo que sea a mí me sigue pareciendo extraño, me produce perplejidad y desazón al tiempo, que el autor no se haga pregunta alguna a todo lo largo de su exposición medular, que parezca estar plena y absolutamente convencido de lo sólido y cierto de su argumentación. ¡Dichoso él! (Martínez, 2002: 76).

Creo que es esta contundencia, esta seguridad a la hora de hacer afirmaciones tan graves, una de las cosas que más puede irritar al lector atento y que hace más preocupantes algunas de sus aseveraciones y sobre todo algunos de sus silencios más clamorosos. Pero comencemos por acercarnos a sus principales ideas.

\section{Un nuevo paradigma en relaciones internacionales: el «choque de civilizaciones»}

Después del derrumbe de la URSS, todo cambió bruscamente en el panorama internacional. La Guerra Fría acababa con el triunfo de uno de sus contendientes y la hegemonía de los EE. UU. parecía incuestionable. Tras el fracaso definitivo del comunismo, el neoliberalismo se convirtió en la ideología dominante, en el «pensamiento único» que legitima el sistema liberal que domina y dirige la globalización económica mundial.

Por lo que se refiere a la nueva situación internacional, la potencia hegemónica hubo de plantearse, a nivel estratégico, cuál iba a ser a partir de ahora su manera de actuar ante las nuevas correlaciones de fuerzas y frente a los nuevos desafíos que se le planteaban al poder estadounidense a nivel mundial. Pronto irán entrando en liza dos posturas bien diferentes, hasta el punto de que a mediados de la década de los años 1990, el Equipo de Asuntos Exteriores del gobierno estadounidense aparecía dividido en dos grandes corrientes ideológicas. ${ }^{1}$ Por un lado los partidarios de una «política multilateral», representados por Colin Powell y el Departamento de Estado, que

${ }^{1}$ Sigo en este punto a Gilles Kepel, que, en el primer capítulo, «La revolución neoconservadora», de un libro reciente (2004: 53-82), hace una buena presentación de dichas corrientes con relación directa al tema que nos ocupa. 
defienden una postura pragmática, la utilización de los instrumentos multilaterales, como la ONU, tratando de hacer valer en ellos el peso preponderante de los EE. UU. Frente a esta corriente, cada vez se va dejando notar con más fuerza la influencia de los neoconservadores en las altas esferas políticas. Sus representantes en Exteriores, con Paul Wolfowitz y un grupo de civiles del Pentágono a la cabeza, son partidarios de una «política unilateral», defendiendo una transformación radical del orden anterior que reflejara la hegemonía estadounidense. Propugnan exportar la «democracia americana» por el mundo utilizando todos los medios necesarios y sin contar con las instancias internacionales que consideran obsoletas. ${ }^{2}$

Con este telón de fondo, y en una situación de gran incertidumbre debida a los profundos cambios habidos en la esfera internacional, van a ir surgiendo nuevos modelos teóricos que tratan de hacerse cargo de la situación mundial emergente.

Entre ellos van a destacar dos planteamientos que serán enormemente publicitados, como son las ya famosas tesis de El fin de la historia de Francis Fukuyama y de El choque de civilizaciones, de Samuel Huntington. ${ }^{3}$

El primero, de Fukuyama, por cierto antiguo alumno de Huntington, era mucho más optimista respecto a la situación mundial, al pensar que tras el derrumbe del comunismo la democracia liberal se quedaba sin rivales alternativos. Con la economía de mercado y la democracia liberal, junto con ciertas instituciones internacionales basadas en leyes, normas y valores comunes como horizonte final, la historia había llegado en lo esencial a su fin. Como escribe Huntington: «Un solo mundo: euforia y armonía. Un paradigma profusamente formulado se basaba en la suposición de que el final de la guerra fría significaba el final de todo conflicto importante en la política global y el comienzo de un mundo relativamente armonioso» (2005: 34 ).

Muy distinto iba a ser el análisis de Huntington, cuyo primer paso a la presentación de su paradigma sería cuestionar la validez explicativa de los posibles modelos alternativos, entre ellos, obviamente, el de Fukuyama, al que reprocha su optimismo injustificado. Ni un solo mundo, ni mucho menos armónico.

\footnotetext{
${ }^{2}$ Kepel cita un más que revelador texto de Paul Wolfowitz, Defense Planning Guidance Paper, de 1992, donde se aboga por la afirmación del poder estadounidense en cualquier parte del mundo donde estén en juego intereses americanos vitales, entre los que destacan el aprovisionamiento del petróleo y la seguridad del Estado de Israel (Kepel, 2004: 60).

${ }^{3}$ El gran éxito mediático de ambos textos -los dos libros se han convertido en auténticos bestsellers-, no es ajeno al contexto de auge de las ideologías neoliberal y neoconservadora. De hecho, importantes grupos industriales y financieros invierten ingentes sumas de dinero en el patrocinio de think-tanks, fundaciones y centros de investigación (como, por ejemplo, la Fundación Olin-Mathieson Chemical Company), con el objetivo de promocionar y legitimar el sistema liberal que dirige la globalización económica mundial (Quintanas, 2002: 239-241). El propio Huntington dirigió hasta el año 2000 el John M. Olin Institute for Strategic Studies, sito en la Universidad de Harvard.
} 
Por lo que respecta a la tesis de Samuel P. Huntington, todo se originó en 1993, en que el politólogo estadounidense, profesor de Ciencias Políticas en la Universidad de Harvard y especialista en Política Internacional, escribió un artículo en la revista Foreign Affairs titulado «The clash of civilizations? $\gg^{4} \mathrm{El}$ artículo, de título provocativo y con gancho periodístico, tuvo un enorme eco publicitario y también recibió importantes críticas, entre otras cosas por presentar en tan pocas páginas un asunto de tanta trascendencia para las relaciones internacionales, por lo que el autor decidió tomarse su tiempo y explicarse mejor. En 1996 apareció un extenso libro, El choque de civilizaciones y la reconfiguración del orden mundial, donde trataba de fundamentar su tesis con amplitud y planteaba un nuevo paradigma para la política global. «El presente libro no es, ni pretende ser, una obra de ciencias sociales. Intenta ser más bien una interpretación de la evolución de la política global tras la guerra fría. Aspira a ofrecer una estructura, un paradigma, para ver la política global» (Huntington, 2005: 14).

Su tesis es que, después de la guerra fría, la política mundial, impulsada por la modernización económica y social, se está reconfigurando de acuerdo con criterios culturales. Desaparecida la política de bloques entre las dos superpotencias, la URSS y los EE. UU., lo que une y separa a los individuos ya no es la ideología, o el interés, sino que ahora el elemento fundamental ha pasado a ser la «identidad».

En el mundo de la posguerra fría, las distinciones más importantes entre los pueblos no son ideológicas, políticas ni económicas; son culturales. Personas y naciones están intentando responder a la pregunta más básica que los seres humanos pueden afrontar: ¿quiénes somos? Y la están respondiendo en la forma tradicional en que los seres humanos la han contestado, haciendo referencia a las cosas más importantes para ellos. La gente se define desde el punto de vista de la genealogía, la religión, la lengua, la historia, los valores, costumbres e instituciones. Se identifican con grupos culturales: tribus, grupos étnicos, comunidades religiosas, naciones y, en el nivel más alto, civilizaciones. La gente usa la política no sólo para promover sus intereses, sino también para definir su identidad [...].

La pregunta: «¿De qué lado estás?» ha ido reemplazada por esta otra, mucho más fundamental: «¿Quién eres?» [...]. «¿Quiénes somos?», «¿adónde pertenecemos?» y «¿quién no es de los nuestros?» [...]. Al

${ }^{4}$ Samuel P. Huntington nació en 1927. Fue fundador y coeditor de la revista Foreign Policy (1970-1977), miembro del Consejo de Seguridad Nacional de la Casa Blanca (1977-1978), director del John M. Olin Institute for Strategic Studies (Universidad de Harvard) (hasta 2000) y Presidente del Harvard Academy for International and Area Studies entre otros cargos. El artículo, significativamente, formaba parte de un proyecto de investigación del Instituto Olin sobre «El entorno de seguridad cambiante y los intereses nacionales americanos». Puede leerse en castellano en (Huntington, 2002). 
habérselas con una crisis de identidad, lo que cuenta para la gente es la sangre y las creencias, la fe y la familia (Ibidem: 22 y 165-166).

Rechazando con vehemencia otro tipo de explicaciones alternativas, singularmente que la modernización económica y social esté produciendo la occidentalización del resto de las sociedades y mucho menos aún una civilización universal. El mundo no tiende a la unidad, del tipo que sea, sino todo lo contrario, las distintas civilizaciones tienen, mantienen y refuerzan sus diferencias sustantivas en cuanto a sus presupuestos filosóficos, valores subyacentes, relaciones sociales, costumbres y puntos de vista globales sobre la vida. Por otro lado, para Huntington, lo repite en numerosas ocasiones, la religión es el elemento definitorio más importante de las civilizaciones -cuatro de las cinco grandes religiones mundiales: cristianismo, islam, hinduismo y confucianismo se asocian con grandes civilizaciones-, por lo que la revitalización de la religión que se estaría produciendo a lo largo del mundo estaría reforzando las diferencias culturales.

En conclusión, que toda la política global va a girar en torno a las civilizaciones. «El tema central de este libro es el hecho de que la cultura y las identidades culturales, que en su nivel más amplio son identidades civilizacionales, están configurando las pautas de cohesión, desintegración y conflicto en el mundo de la posguerra fría» (Ibidem: 20).

Pues si bien los Estados-nación, reconoce Huntington, siguen siendo los actores principales de los asuntos mundiales, éstos definen sus intereses cada vez más desde la perspectiva civilizacional. «Por primera vez en la historia, la política global es a la vez multipolar y multicivilizacional», sentencia Huntington. Señalando la existencia de unas siete u ocho civilizaciones que agruparían a los aproximadamente 340 Estados existentes: China o sínica, Japonesa, Hindú, Islámica, Ortodoxa, Occidental, Latinoamericana y, posiblemente, escribe, Africana.

Por otra parte, está cambiando el equilibrio de poder entre las civilizaciones. La modernización, e inclusive la democratización, en su extensión por el mundo están fortaleciendo las culturas autóctonas y reduciendo la influencia y el poder relativos de Occidente. La fase de influencia unilateral de Occidente sobre el resto está siendo sustituida por una fase de interacciones intensas y sostenidas entre todas las civilizaciones en múltiples direcciones.

Y a esta reafirmación cultural e identitaria frente a Occidente está contribuyendo de manera decisiva la reafirmación religiosa que se está produciendo a lo largo del mundo. Pues para Huntington la religión tiene una gran importancia en el mundo moderno: «la religión es una fuerza fundamental, quizá la fuerza fundamental, que motiva y moviliza a la gente» (2005: 84). Se opone, por tanto, a aquellos «analistas que restan importancia a este factor», sobre todo desde la perspectiva de su tesis. «Milenios de historia humana han demostrado que la religión no es una "pequeña diferencia", sino posiblemente la diferencia más profunda que puede existir entre la gente» (Ibi- 
dem: 344). Con la religión sucede lo mismo que con la cultura en general, que viene a ser aquello que sobre todo separa y divide a los seres humanos. De hecho para Huntington, y con ello podemos decir que se cierra el círculo, «dado que la religión es la principal característica definitoria de las civilizaciones, las guerras de línea de fractura se producen casi siempre entre pueblos de religiones diferentes» (Idem).

Pero es que, además, la religión está «resurgiendo» a lo largo de todo el mundo, si bien reconoce que su «fuerza relativa no ha cambiado espectacularmente». ¿Cuál es la razón que explica este resurgir de la religión? Para él está claro, pues lo repite numerosas veces: la causa más obvia son «los procesos de modernización social, económica y cultural que se difundieron por todo el mundo en la segunda mitad del siglo XX» (Ibidem: 126). Lo que se reaviva en el seno de las grandes religiones es un tipo de religiosidad tradicional, y los movimientos fundamentalistas sólo representan una «ola superficial» de una marea religiosa muchísimo más amplia. Una religión con un cariz profundamente conservador, que cumple una función compensadora de los «traumas» que causa la modernidad en los individuos, pues la modernidad supone la ruptura de las relaciones tradicionales e implica una crisis de identidad en ellos, les produce extrañamiento y anomia, y la religión les proporciona la identidad que precisan. Sobre todo va a subrayar la gran importancia del «renacimiento islámico», movimiento generalizado y de carácter mayoritariamente moderado, al que califica de acontecimiento histórico trascendental, que afecta a una quinta parte de la humanidad, y que «al menos es tan trascendental como la Revolución americana, la Revolución francesa o la Revolución rusa [...] y que es semejante y comparable a la Reforma protestante en la sociedad occidental» (Huntington, 2005: 145n). Renacimiento religioso que, como en el caso de las demás religiones no occidentales, es un producto de la modernización y a la vez un enfrentamiento a ella. Tales religiones suponen un rechazo no tanto de la modernización como de la occidentalización.

El resurgimiento religioso en todo el mundo es una reacción contra el laicismo, el relativismo moral y los excesos, y una reafirmación de los valores del orden, la disciplina, el trabajo, la ayuda mutua y la solidaridad humana $[. .$.$] .$

Además de los traumas psicológicos, emocionales y sociales de la modernización, otros estimulantes del renacimiento religioso serían la retirada de Occidente y el final de la guerra fría $[. .$.$] .$

${ }^{5}$ De hecho, las cifras (porcentajes) que él mismo maneja no avalan tal resurgimiento, al menos, numérico. Entre 1970 y las estimaciones previstas para el 2000, el total de cristianos desciende en un $1,4 \%$, los musulmanes aumentan en un $3,9 \%$, y los «sin religión» aumentan también un $2,1 \%$. Para el mismo periodo, los religiosos en total descienden un $1,5 \%$ mientras que los «sin religión» y los ateos aumentan en un 1,7\% (Huntington, 2005: $82)$. 
La religión ha tomado el relevo a la ideología, y el nacionalismo religioso reemplaza al nacionalismo laico. Los movimientos favorables al renacimiento religioso son antilaicos, antiuniversalistas y, salvo en sus manifestaciones cristianas, antioccidentales [...]. Por lo general no rechazan la urbanización, la industrialización, el desarrollo, el capitalismo, la ciencia ni la tecnología [...].

El renacimiento de religiones no occidentales es la manifestación más intensa de antioccidentalismo de las sociedades no occidentales. Dicho renacimiento no es rechazo de la modernidad; es rechazo de Occidente y de la cultura laica, relativista y degenerada asociada con Occidente. Es un rechazo de la llamada «occidentoxicación» de las sociedades no occidentales. Es una declaración de independencia cultural respecto a Occidente, una declaración orgullosa: «Queremos ser modernos, pero no queremos ser vosotros» (Huntington, 2005: 128, 130, 131 y 133). ${ }^{6}$

Pero no es sólo que múltiples identidades culturales y civilizacionales configuren por completo el nuevo mundo, sino que las civilizaciones al reafirmarse y pretender extenderse -Huntington se refiere sobre todo a Occidente y al islam-, parecen condenadas a chocar entre sí. El concepto de «choque de civilizaciones» lo toma de Bernard Lewis, cuyas palabras, escritas al analizar «Las raíces de la ira musulmana», son citadas tanto en el artículo inicial como en el libro. El desafío al que nos enfrentamos, apuntaba Lewis...

Es nada menos que un choque de civilizaciones - esa reacción quizá irracional, pero ciertamente histórica, de un antiguo rival contra nuestra herencia judeo-cristiana, nuestro presente laico y la expansión de ambos por todo el mundo-. Es de importancia crucial que, por nuestra parte, eso no nos mueva a una reacción igualmente histórica, pero también igualmente irracional, contra ese rival (Citado por Huntington, 2005: 285).

El núcleo fundamental de su tesis, lo reconoce Huntington y no en vano da título a sus dos textos, radica en ese más que previsible «choque»: «mi

${ }^{6}$ En otro lugar (Urrutia, 2007), me he ocupado de esta presunta «vuelta» de la religión que, muy especialmente en el caso del fundamentalismo, se trata más bien del fracaso político y social de la modernización. «El fundamentalismo es el fruto de una modernización desarraigadora, a cuyo extravío ha contribuido decisivamente nuestra historia colonial y una descolonización fracasada» (Habermas, 2006: 110). La religión, en esta época de «reconfiguración global» se convierte en un lugar privilegiado de lo político, de su instrumentalización. Estos movimientos, «lejos de manifestar un «retorno de lo religioso», atestiguan su desaparición, señalando un vacío, un déficit de la política en el momento presente, masivo y cruel, que carecería incluso de términos políticos que permitirían expresarla. De ahí el recurso a lo religioso, como registro del discurso, como lenguaje» (Michel, 1994: 108). Quizás sea por esta instrumentalización de la religión al servicio de la «identidad», o como mitigadora de los «traumas de la modernidad», por lo que Huntington se permite decir que el «paradigma civilizatorio» podría haber predicho el aumento del fundamentalismo a lo largo del mundo (2005: 43). 
tesis de que la dimensión fundamental y más peligrosa de la política global que está surgiendo sería el conflicto entre grupos de civilizaciones diferentes» (Ibidem: 13). De hecho, Huntington cree que ya nos encontramos en una fase de «cuasiguerra» entre civilizaciones. Los peligros fundamentales radican en las pretensiones universalistas de Occidente, en el islam -«convencido de la superioridad de su cultura y obsesionado con la inferioridad de su poder»- y en China.

Es probable que en el futuro los choques más peligrosos surjan de la interacción de la arrogancia occidental, la intolerancia islámica y la autoafirmación sínica [...].

Mientras que, en el plano macro o global de la política mundial, el choque fundamental de civilizaciones se da entre Occidente y las demás, en el plano micro o local se da entre el islam y las demás (Ibidem: 243 y 346).

Y es sobre todo el islam - no el fundamentalismo islámico, apostilla, sino la civilización islámica como tal- el elemento más desestabilizador, pues ha sido de hecho, lo que apoya con datos empíricos, el que ha estado en los últimos tiempos envuelto en más conflictos violentos con las demás civilizaciones. Y no duda en reiterar, considerándola probada, una afirmación de su artículo que fue enormemente polémica: «El islam tiene unas fronteras sangrientas» (Ibidem: 349n).

Pero si bien una guerra entre Occidente y el resto de las civilizaciones no es inevitable, sí que es posible (Ibidem: 410), por lo que al final de su libro establecerá tres normas de actuación que, a su juicio, pudieran contribuir a evitarla. Principalmente la «norma de abstención», es decir, que «los Estados centrales deben evitar intervenir en conflictos dentro de otras civilizaciones» (Ibidem: 431), y la «norma de los atributos comunes» por la que «los pueblos de todas las civilizaciones deben buscar e intentar ampliar los valores, instituciones y prácticas que tienen en común con los pueblos de otras civilizaciones» (Ibidem: 436).

Tema este último de los «atributos comunes», decisivo, y sobre el que volveremos en detalle más adelante al repasar críticamente los planteamientos de base más débiles y cuestionables del planteamiento de Huntington.

\section{El desafío de la diversidad cultural}

Inicialmente, la diversidad cultural, uno de los más importantes desafíos de nuestro mundo globalizado, puede ser vista bien como algo positivo, como una oportunidad de enriquecimiento mutuo para las personas y los grupos, o bien como algo negativo, como un riesgo permanente de conflictos sociales. Huntington renuncia prácticamente a la primera de las posibilidades en su análisis y siempre tiende a ver al «otro» como un peligro potencial. 
Es verdad que Huntington se hace eco de una serie de hechos, lo que se ha convenido en englobar bajo la denominación de «políticas de la identidad», que desgraciadamente están a la orden del día en nuestro convulso mundo globalizado. Como reconoce el Informe sobre Desarrollo Humano de la ONU para 2004:

La novedad, hoy, es el surgimiento de la política de la identidad. En contextos muy diferentes y de modos también diversos [...], la gente vuelve a movilizarse en torno a antiguos resentimientos de carácter étnico, religioso, racial y cultural y exige el reconocimiento, la valoración y la acogida de su identidad por parte de la sociedad en su conjunto [...]. De no abordar las luchas por la identidad cultural o abordarlas en forma inadecuada, podrían transformarse rápidamente en una de las fuentes más importantes de inestabilidad al interior de los Estados y entre ellos, lo que podría, a su vez, desencadenar un conflicto cuya consecuencia sea el retroceso del desarrollo (PNUD, 2004: 1). ${ }^{7}$

La clave está por lo tanto en cómo analizamos y abordamos esa diversidad cultural para que podamos convivir y enriquecernos mutuamente con las diferencias, a través de la unidad en la convivencia, y para que contribuyamos a mitigar en lo posible la previsible «conflictividad cultural». Pero el libro de Huntington dedica varios cientos de páginas a alertarnos del peligro de la confrontación entre civilizaciones y sólo al final, en unas breves páginas, aborda el problema decisivo de la convivencia entre diferentes y se plantea si hay unos valores comunes que nos permitan «evitar la guerra» entre las civilizaciones.

Uno de los aspectos más problemáticos del texto de Huntington es el operar con una delimitación clara y nítida de los conceptos de cultura y civi-

${ }^{7}$ El Informe del PNUD, titulado La libertad cultural en el mundo diverso de hoy, es un documento ciertamente valioso para contrarrestar algunas de las principales afirmaciones de base (sociológicas, antropológicas, etc.) que realiza Huntington, y sus consecuencias políticas, éticas, etc., sobre la problemática de la diversidad cultural. Y para reflexionar sobre la manera correcta de abordarla, lo que pasa, en gran medida, por un planteamiento integral del desarrollo humano a nivel mundial. De hecho, el informe, al abordar esa problemática decisiva, reacciona ante algunas formas inadecuadas y peligrosas de plantear los conflictos culturales y a menudo tiene presente, de forma implícita y a veces explícita, los planteamientos de Huntington. Como escriben sus autores en el Prefacio: «En una época en la que el concepto de "choque cultural" resuena con fuerza y de manera inquietante en todo el mundo, recobra particular importancia encontrar respuestas a la antigua pregunta de cómo manejar y atenuar de mejor forma los conflictos en torno al idioma, la religión, la cultura y la etnia [...]. Así como algunas ideas concretas sobre lo que significa en la práctica la idea de formar y administrar la política de la identidad y la cultura de una manera coherente con los principios fundamentales del desarrollo humano». Lo que implica el rechazo de aquellas afirmaciones que sostienen que «las diferencias culturales necesariamente generan conflictos sociales, económicos y políticos» (PNUD, 2004: v). 
lización, ignorando la gran riqueza y pluralidad interna de cada civilización y la multiplicidad de interacciones históricas entre ellas, llegando incluso a veces, a juicio de Edward Said, a la caricatura:

En realidad, Huntington es un ideólogo, alguien que pretende convertir las «civilizaciones» y las «identidades» en lo que no son, entidades cerradas y aisladas de las que se han eliminado las mil corrientes y contracorrientes que animan la historia humana y que, a lo largo de siglos, han permitido que la historia hable no sólo de guerras de religión y conquistas imperiales, sino también de intercambios, fecundación cruzada y aspectos comunes (Said, 2001: 23).

Tal delimitación precisa sobre dónde empiezan y acaban unas y otras civilizaciones es, sobre todo, enormemente problemática y está llena de inquietantes consecuencias en la actualidad compleja en que vivimos, donde la interacción entre los seres humanos es más intensa que nunca, y donde los contactos entre ideas, valores o formas de vida se han acrecentado y profundizado como jamás en la historia de la humanidad.

En 2004, el citado Informe del PNUD se hacía eco a la perfección de las numerosas críticas realizadas a Huntington en esa dirección, con un planteamiento crítico de fondo amplio y radical.

Un problema básico de estas teorías es el supuesto implícito de que la cultura es en gran medida fija e invariable, lo que permite que el mundo se divida perfectamente en «civilizaciones» $\mathrm{O}$ «culturas». Esto ignora el hecho de que aunque existe una gran continuidad en los valores y tradiciones de las sociedades, las culturas también cambian y rara vez son homogéneas [...]. Paradójicamente, justo en el momento en que los antropólogos descartan el concepto de cultura como fenómeno social claramente delimitado y fijo, surge un creciente interés desde la política convencional por descubrir los valores y rasgos esenciales de un «pueblo y su cultura» [...].

... la amenaza de un «choque de civilizaciones» (como lo denomina Samuel Huntington) es otro temor que ha suscitado gran interés durante los últimos años [...]. ¿Pero es realmente sólido el análisis cultural implícito en ese temor? ¿Y es confiable la interpretación de la historia en la que se funda tal análisis cultural? Existen motivos para dudar de ambos postulados. Las distinciones entre las diversas categorías de civilización no son tan claras ni llanas como se quiere aparentar y la historia simulada que sustenta la tesis del choque de civilizaciones exagera tales contrastes, en parte por dejar de lado las diferencias que existen al interior de cada cultura, pero también por ignorar las interacciones históricas entre las distintas culturas $[\ldots]$.

Las rígidas distinciones que se han establecido últimamente para dar forma al temor al choque de civilizaciones son ciegas a las enseñanzas de la historia mundial. Las categorizaciones a menudo se basan en una inocencia histórica extrema y extraordinariamente burda. Se ignora de ma- 
nera eficaz la diversidad de tradiciones dentro de las distintas civilizaciones y se pasan por alto las intervenciones mundiales de gran alcance en ciencias, tecnología, matemáticas y literatura realizadas durante varios milenios para otorgar credibilidad a una visión parroquial que arguye la singularidad de la civilización occidental (PNUD, 2004: 5, 21 y 22).

Por otro lado, parece que en todo momento, no sabemos si para hacer valer su tesis, haya de llevar hasta el extremo la polarización grupal, producida por las políticas de la identidad, entre el «nosotros» y el «ellos», y olvide que los límites entre el «nosotros» y el «ellos»son móviles y pueden desaparecer para incorporar a grupos más amplios de personas. El «otro» nunca es visto por Huntington como una diferencia que me pudiera enriquecer sino como una amenaza permanente, como un enemigo potencial.

Para los pueblos que buscan su identidad y reinventan la etnicidad, los enemigos son esenciales, y las enemistades potencialmente más peligrosas se darán a lo largo de las líneas de fractura existentes entre las principales civilizaciones del mundo [...].

Sabemos quiénes somos sólo cuando sabemos quiénes no somos, y con frecuencia sólo cuando sabemos contra quiénes estamos [...].

Las civilizaciones son el «nosotros» más grande dentro del que nos sentimos culturalmente en casa, en cuanto distintos de todos los demás «ellos» ajenos y externos a nosotros [...].

... La ubicuidad del conflicto. Es humano odiar. Por propia definición y motivación, la gente necesita enemigos: competidores en los negocios, rivales en el rendimiento académico, oponentes en política (Huntigton, 2005: 20, 22, 51 у 172).

Anna Quintanas ha aludido a esta visión antropológica negativa y profundamente maniquea que subyace en todo momento a la argumentación de Huntington. «Los hombres de Estado y los investigadores deben reconocer como verdad universal que, para amar lo que somos, tenemos que odiar lo que no somos. [...]. No parece que Huntington pueda llegar a imaginar, ni remotamente, que la humanidad también puede ser el reconocimiento de uno mismo en el otro, y con el otro» (2002: 248).

Todo lo anterior va unido a una concepción subyacente de la «identidad» como exclusiva y fijada de una vez por todas a su propio grupo, o en último caso a la civilización en su conjunto, y que además ha de distinguirse de forma completa y nítida de la de las otras civilizaciones.

Frente a lo cual hemos de defender que la identidad no es única, exclusiva, y que además se le imponga a uno desde fuera sin posibilidad alguna de elección, sino que el individuo puede tener y de hecho tiene múltiples identidades diferentes que trata de conjugar en su propia vida.

... los comunitarios tienen razón en subrayar la importancia que tiene el sentido de identidad en guiar la propia vida, aunque no resulta tan 
claro cómo la identidad puede consistir tan sólo en descubrir algo acerca de uno mismo en lugar de ejercer una opción, ya sea de manera explícita o por implicación. Estas elecciones se realizan constantemente con absoluta conciencia, la mayor parte de las veces en forma implícita pero en ocasiones también de manera explícita [...].

Cada individuo suele identificarse con muchos grupos distintos. Una persona puede tener la identidad que le otorga su ciudadanía (como ser francesa), género (ser mujer), raza (tener origen chino), ascendencia regional (haber llegado de Tailandia), lengua (dominar el tai, chino e inglés, además del francés), afiliación política (ser de orientación izquierdista), religión (ser budista), profesión (ser abogada), ubicación (ser parisina), afiliación deportiva (ser jugadora de bádminton y fanática del golf), preferencias musicales (gustar del jazz y el hip-hop) y literarias (entretenerse con novelas policiales), hábitos alimentarios (ser vegetariana), entre otros [...].

Negar la posibilidad de elección cuando ésta existe no sólo significa un error de interpretación de lo que el mundo es en realidad, sino que constituye además un delito ético y el abandono político de la responsabilidad (PNUD, 2004: 17 y 22).

Amin Maalouf, en esta misma dirección, ha escrito páginas preciosas en un valiente libro, con el significativo título de Identidades asesinas, denunciando la concepción tribal de la identidad, la reducción de la identidad a una sola dimensión, con lo que se insta a los hombres a una actitud parcial, intolerante y fanática.

Una visión de los seres humanos que está muy extendida y que a mi juicio es peligrosa. Cuando me preguntan qué soy «en lo más hondo de mí mismo», están suponiendo que «en el fondo» de cada persona hay sólo una pertenencia que importe, su «verdad profunda» de alguna manera, su «esencia», que está determinada para siempre desde el nacimiento y que no se va a modificar nunca; como si lo demás, todo lo demás -su trayectoria de hombre libre, las convicciones que ha ido adquiriendo, sus preferencias, su sensibilidad personal, sus afinidades, su vida en suma-, no contara para nada. Y cuando a nuestros contemporáneos se los incita a que «afirmen su identidad», como se hace hoy tan a menudo, lo que se les está diciendo es que rescaten del fondo de sí mismos esa supuesta pertenencia fundamental, que suele ser la pertenencia a una religión, una nación, una raza o una etnia, y que la enarbolen con orgullo frente a los demás [...].

Si se las insta continuamente a que elijan un bando u otro, si se las conmina a reintegrarse en las filas de su tribu, entonces es lícito que nos inquietemos por el funcionamiento del mundo [...]. ¿Quién las conmina? No sólo los fanáticos y los xenófobos de todas las orillas: también tú y yo, todos nosotros. Por esos hábitos mentales y esas expresiones que tan arraigados están en todos nosotros, por esa concepción estrecha, exclusivista, beata y simplista que reduce toda identidad a una sola pertenencia que se proclama con pasión. ¡Así es como se «fabrica» a los autores de las matanzas! -me dan ganas de gritar (Maalouf, 1999: 12-13, 15-16). 
Bellas y acertadas palabras de Maalouf, escritas poco después del libro de Huntington, y sin duda redactadas teniendo muy presentes los presupuestos subyacentes a la tesis del «choque de civilizaciones». La identidad no es única, grita a los cuatro vientos Maalouf, no se nos da de una vez por todas, sino que es «múltiple» y esa identidad sui géneris, formada como un puzle por múltiples identidades parciales, la vamos construyendo y transformando continuamente a lo largo de nuestra vida. ¡Es urgente que elaboremos una «nueva concepción de la identidad» compuesta por múltiples pertenencias!, reclama Maalouf.

Desde el momento en que concebimos nuestra identidad como integrada por múltiples pertenencias, unas ligadas a una historia étnica y otras no, unas ligadas a una tradición religiosa y otras no, desde el momento en que vemos en nosotros mismos, en nuestros orígenes y en nuestra trayectoria, diversos elementos confluyentes, diversas aportaciones, diversos mestizajes, diversas influencias sutiles y contradictorias, se establece una relación distinta con los demás, y también con los de nuestra propia «tribu». Ya no se trata simplemente de «nosotros» $\mathrm{y}$ «ellos», como dos ejércitos en orden de batalla que se preparan para el siguiente enfrentamiento, para la siguiente revancha. Ahora, en «nuestro» lado hay personas con las que en definitiva tengo muy pocas cosas en común, y en el lado de «ellos» hay otras de las que puedo sentirme muy cerca $[\ldots]$.

En la época de la mundialización, con ese proceso acelerado, vertiginoso, de amalgama, de mezcla, que nos envuelve a todos, es necesario - $i \mathrm{y}$ urgente!- elaborar una nueva concepción de la identidad. No podemos limitarnos a obligar a miles de millones de personas desconcertadas a elegir entre afirmar a ultranza su identidad y perderla por completo, entre el integrismo y la desintegración. Sin embargo, eso es lo que se deriva de la concepción que sigue dominando en ese ámbito. Si a nuestros contemporáneos no se los incita a que asuman sus múltiples pertenencias, si no pueden conciliar su necesidad de tener una identidad con una actitud abierta, con franqueza y sin complejos, ante las demás culturas, si se sienten obligados a elegir entre negarse a sí mismos y negar a los otros, estaremos formando legiones de locos sanguinarios, legiones de seres extraviados (Maalouf, 1999: 44 y 48-49).

Retengamos las expresiones que Maalouf critica con total radicalidad (tribu, ejército, batalla, etc.), la concepción dominante en ese ámbito, como él mismo dice, y volvamos al texto de Huntington, donde son utilizadas con total naturalidad, sin tratar de conjurarlas, y fijémonos además cómo su resultado lógico no puede ser otro que el «enfrentamiento» del que habla Maalouf.

Las civilizaciones son el «nosotros» más grande dentro del que nos sentimos culturalmente en casa, en cuanto distintos de todos los demás «ellos» ajenos y externos a nosotros [...]. 
En un mundo donde la cultura cuenta, los pelotones son tribus y grupos étnicos, los regimientos son naciones, y los ejércitos, civilizaciones [...].

Las civilizaciones son las últimas tribus humanas y el choque de civilizaciones es un conflicto tribal a escala planetaria (Huntington, 2005: 51, 170 y 277).

De hecho, Huntington no sólo habla de la importancia de las civilizaciones en el nuevo contexto mundial, sino del «choque de civilizaciones». Y «decir "choque de civilizaciones" equivale a augurar la confrontación cultural-religiosa como nuestro próximo futuro» (Mardones, 1998: 121). Ya se ha llamado la atención en varias ocasiones sobre el signo de interrogación dejado por Huntington en el tintero en el camino que va desde el artículo (1993) al libro (1996). Incluso en su artículo inicial llegaba a preguntarse «por qué han de chocar las civilizaciones» (why civilizations will clash) (Huntington, 2002: 23); luego parece clara su opinión, aunque, seamos justos, su pretensión es tratar de imaginar, lo hace al final de su libro y pronto hablaremos sobre ello, cómo podríamos evitar a pesar de todo el, a su parecer más que probable, «choque de civilizaciones».

Aún debemos de profundizar un poco más en la crítica a la predisposición de Huntington, en la lógica de su argumentación, a considerar que la diversidad cultural, siempre presentada de forma extrema, conduce casi inevitablemente a un choque entre valores irreconciliables.

Una forma muy común de explicar la violencia es aquella que señala las diferencias culturales o étnicas como responsables principales de los conflictos, arguyendo para ello cierta propensión innata entre las personas de culturas diferentes a luchar unos contra otros por la dominación y la autonomía ante diferencias sobre valores que resultan incompatibles. Tal postura está muy bien retratada en la conocida predicción de Samuel Huntington del «choque de civilizaciones» $[\ldots]$.

Este argumento también desvía la atención de importantes factores económicos y políticos [...].

Muchos conflictos son, en efecto, de orden cultural, puesto que la gente que opta por cada uno de los lados de estas guerras siente que pertenece a una misma cultura. Pero las causas primarias de las guerras muy raramente son las culturas propiamente tales o una incompatibilidad de valores. Investigaciones recientes proponen dos explicaciones diferentes: la codicia y las desigualdades horizontales. La lucha por el control de valiosos recursos naturales como el petróleo o las minas de diamantes podría ser la causa primordial de las guerras étnicas, como en el caso de Liberia, Sierra Leona y Sudán [...].

Las investigaciones recientes muestran que muchos conflictos han estallado en situaciones de acceso desigual de los grupos a bienes económicos, oportunidades de ingreso o empleo, servicios sociales u oportunidades políticas (PNUD, 2004: 41-42). 
En el fondo de todo lo que llevamos dicho hasta el momento late un «determinismo cultural» que ha de ser rechazado, no sólo por ser la mayoría de las veces unilateral desde un punto de vista epistemológico, sino por ser además peligroso en sus consecuencias políticas. Por «determinismo cultural» queremos decir el hacer de la cultura la variable que explica, por sí sola, las diferencias políticas, económicas o sociales entre los colectivos. Atribución que si ya es muy problemática en el caso específico de la democracia, «La cultura islámica explica en gran medida la incapacidad de la democracia para abrirse paso en buena parte del mundo musulmán» (Huntington, 2005: 24) ${ }^{8}$; en su sentido más radical, que hace referencia al desarrollo económico y social, es prácticamente insostenible: «Las diferencias importantes entre civilizaciones en materia de desarrollo político y económico están claramente enraizadas en sus diferentes culturas» (Idem), escribe Huntington. O recordemos lo trascrito en otro lugar: «En el mundo de la posguerra fría, las distinciones más importantes entre los pueblos no son ideológicas, políticas ni económicas; son culturales. Personas y naciones están intentando responder a la pregunta más básica que los seres humanos pueden afrontar: ¿quiénes somos?» (Ibidem: 22). Como si no existiera otra pregunta mucho más básica aún para millones de personas a lo largo del mundo: ¿cómo puedo sobrevivir?

El supuesto de que la categoría de civilización es la única distinción importante y que ésta debe eliminar cualquier otra forma de identificar a las personas implica un problema metodológico fundamental. Todas las demás distinciones (como entre ricos y pobres, miembros de diferentes clases y ocupaciones, personas de diferentes ideologías políticas, diferentes nacionalidades y lugares de residencia, entre grupos que se identifican por su lengua y muchas más) quedan eliminadas tras la supuesta preeminencia de esta forma de concebir las diferencias entre las personas. Como

\footnotetext{
${ }^{8}$ Véase también la p. 152. Lo que encuestas actuales sobre la opinión de los musulmanes parecen contradecir: «las conclusiones más recientes del Estudio Mundial de Valores indican que las personas de los países musulmanes apoyan los valores democráticos tanto como aquellas de los países no musulmanes» (PNUD, 2004: 5). De gran interés es la más reciente, realizada por The Pew Global Project, que recaba la opinión de los musulmanes en 13 países, incluidos varios occidentales. En ella podemos leer cómo «no existe un conflicto entre ser un musulmán devoto y vivir en una sociedad moderna» para el $49 \%$ de los musulmanes británicos, el 57\% de los musulmanes alemanes, el 72\% de los musulmanes franceses y el $71 \%$ de los musulmanes españoles; el 52\% de los indonesios, el $63 \%$ de los jordanos, $60 \%$ de los turcos, el $73 \%$ de los egipcios o el $64 \%$ de los musulmanes nigerianos (p. 3). O que están de acuerdo con que «la democracia puede funcionar bien» «en la mayoría de los países musulmanes» el $80 \%$ de los musulmanes alemanes, el $76 \%$ de los musulmanes franceses, el 59\% de los musulmanes británicos y el 57\% de los musulmanes españoles; y con que puede hacerlo «en su país», el 74\% de los jordanos, el 70\% de los indonesios, el $65 \%$ de los egipcios, el $50 \%$ de los pakistaníes o el $40 \%$ de los turcos (p. 5) (<www.pewglobal.org $>$ ).
} 
si no fuera suficiente que aquellos que buscan fomentar la confrontación global o la violencia sectaria local intenten imponer una identidad divisoria y unitaria preseleccionada a las personas reclutadas como peones de la brutalidad política. Tal imposición se ve fortalecida por el respaldo implícito que los guerreros obtienen de las teorías de categorización única de los pueblos del mundo (PNUD, 2004: 22). ${ }^{9}$

El «paradigma» de Huntington, desde luego, más allá de su validez parcial, no puede admitirse como exclusivo - parece ser así como pretende aplicar a la ciencia política la aportación kuhniana, como si toda ciencia madura se basara en la preeminencia de un único paradigma, lo que es totalmente incorrecto-, si queremos explicar la política global.

Ésa es la opinión, por ejemplo, de Hala Mustafa, quien, en relación con la vertiente más específicamente religiosa que Huntington sitúa tras el «choque de civilizaciones», escribe lo siguiente:

Aunque no hay que subestimar la posibilidad de un enfrentamiento entre Occidente y el islam, no podemos buscar únicamente las raíces del problema en factores religiosos o culturales, como pretende Huntington. Los numerosos agravios políticos y económicos inherentes a las relaciones entre el Norte y el Sur, los ricos y los pobres, deberían hacernos pensar que la religión es más bien el vehículo de la expresión de esos agravios que su causa [...]. Se trata de todo un síntoma de crisis social que no se debe tanto a la religión en sí como al fracaso de unos modelos de desarrollo que no han producido igualdad social (2003: 130).

En realidad, la invocación casi exclusiva a los elementos culturales e identitarios, sin que neguemos su importancia, tiende a minusvalorar aquellos otros que ciertamente son decisivos como los económicos, políticos, sociales o ideológicos. Como escribió el sociólogo Daniel Bell, en un artículo en que criticaba severamente el artículo inicial de Huntington:

En resumen, toda la argumentación me parece improbable, dudosa y llena de contradicciones internas. Es una declaración apocalíptica, arrolladora en sus frases retóricas, que confunde la cultura con la política, y -lo más sorprendente de todo- que pasa por alto la economía (Bell, 1994: 10).

Tal desprecio de variables esenciales, por otro lado, no es inocente. En el fondo se trata de un encubrimiento ideológico que sirve a determinados

${ }^{9}$ Escribe Huntington: «Para la mayoría de los propósitos, el mundo es demasiado complejo para que resulte útil considerarlo simplemente dividido económicamente entre Norte y Sur, o culturalmente entre Este y Oeste» (p. 37). Es curioso cómo a Huntington el mundo no le parece «demasiado complejo» para considerarlo simplemente dividido en siete u ocho civilizaciones. 
intereses económicos y geoestratégicos. La progresiva marginación de factores tan fundamentales sirve a un neoconservadurismo que en realidad deja a salvo de responsabilidad a un proceso de globalización neoliberal profundamente injusto (Mardones, 1998: 133-135).

\section{4. ¿Una civilización universal?}

Nos queda por abordar un aspecto decisivo para acabar de presentar la tesis de Huntington, que nos permitirá además introducir una crítica sustantiva que, de alguna manera, reasume todas las anteriores. ¿Existe, aunque sea de manera incipiente, una «civilización universal»? «La idea implica, en general, la confluencia de la humanidad y la creciente aceptación de valores, creencias, orientaciones, prácticas e instituciones comunes por pueblos y personas de todo el mundo» (Huntington, 2005: 69). Es decir, que las diferentes civilizaciones puedan convivir sin necesidad de «chocar». El propio Huntington presenta bastante bien el grave problema implícito en todo su planteamiento de fondo al recoger, en una nota a pie de página, una crítica de Hayward Alker a su artículo de 1993, en el sentido de que, al identificar cultura y civilización, lo que hacía era rechazar «por definición» la idea de civilización mundial, y concluye: «En este capítulo, sin embargo, suavizo esa definición para permitir la posibilidad de que pueblos de todo el mundo se identifiquen con una cultura planetaria distinta que complemente o sustituya a las civilizaciones en sentido occidental, islámico o sínico» (Ibidem: 70n). Ahora bien, uno no puede dejar de preguntarse: ¿lo hace realmente?, y la respuesta, tras la lectura de su libro, es que Huntington no cambia nada sustantivo que le permita hacer lo que dice. Y que, como ya adelantábamos, sólo al final, sorpresivamente, en contra de muchos de los supuestos que hemos ido criticando, aborda la cuestión de una manera más adecuada aunque, a nuestro juicio, claramente insuficiente. Veamos, por ahora, cómo se instala en una perpetua contradicción al escribir cómo «la idea de civilización en singular ha reaparecido en el argumento de que hay una civilización mundial universal. Este argumento es insostenible, pero resulta útil para examinar (como se hará en el último capítulo de este libro) si las civilizaciones se van haciendo más civilizadas o no» (Ibidem: 48). ¿Cómo podríamos comprobar siquiera el «grado de civilización» de cada una de las civilizaciones, si no admitimos que existe «algo» que hace posible esa comparación? Pero no hay nada semejante en toda su amplísima argumentación. Como escribe a continuación, «una civilización es una entidad cultural», y acuerda con Braudel en que es «engañoso pretender, a la manera alemana, separar la cultura de la civilización que le sirve de fundamento» (Braudel). Para concluir: «Tanto "civilización" como "cultura" hacen referencia a la forma global de vida de un pueblo, y una civilización es una cultura con mayúsculas» (Ibidem: 49). 
De hecho, las opiniones contrarias a tal identificación estricta entre cultura y civilización son despachadas con desdén -como, por ejemplo, la de Havel, quien propone restringir el uso del término civilización al plano mundial y usar los de cultura o subcivilización para las culturas más amplias-, pues le parece que no hace sino crear «confusión semántica»; e igualmente hace con las distintas posibilidades de concebir la existencia de una civilización universal que no se toma muy en serio. ${ }^{10}$

Y así, si no hay atisbo de tal civilización universal, tras dicha denominación sólo queda la posibilidad lógica de que una de las civilizaciones existentes, la occidental, se haga pasar por tal sin serlo realmente.

El concepto de civilización universal sirve para justificar la dominación cultural de otras sociedades por parte de Occidente y la necesidad de que dichas sociedades imiten las prácticas e instituciones occidentales. El universalismo es la ideología de Occidente en sus confrontaciones con las culturas no occidentales (Ibidem: 83).

Huntington, en buena lógica, acaba por defender un relativismo cultural o civilizacional radical. Hasta el punto de que es incapaz de concebir siquiera algún tipo de universalismo legítimo. «El imperialismo es la necesaria consecuencia lógica del universalismo» (Ibidem: 422), escribe. Y no podría ser de otra manera porque para él valores como los derechos humanos y la democracia son, no ya producto de Occidente, que lo son, o cuestionados por su presunta universalidad, que también lo son, sino valores tan sólo válidos para dicha civilización y por lo tanto sólo se pueden universalizar mediante su imposición, lo que es imperialismo. Recientemente su discípulo Fukuyama ha insistido precisamente sobre este punto en un epílogo a la nueva edición de El fin de la historia, aludiendo a que muchos le habían comparado con Huntington pero que hay un aspecto fundamental que les diferencia:

Se trata de la cuestión sobre si los valores y las instituciones desarrollados durante la Ilustración occidental son universales en potencia (como creían Hegel y Marx) o si están limitados a un horizonte cultural (lo cual coincide con las ideas de filósofos posteriores como Friedrich Nietzsche o Martin Heidegger). Sin duda, Huntington considera que no son universales. Aduce que las instituciones políticas con las que estamos familiarizados en Occidente son el producto secundario de un cierto tipo de cultura

${ }^{10}$ Menciona los cuatro sentidos de esa virtual «civilización universal»: 1. Una posible moralidad mínima compartida, lo que no es nuevo ni hace al caso sentencia. 2. Un modo de vida urbano común. 3. Supuestos, valores y doctrinas occidentales compartidos por otras civilizaciones. Lo que llama la «cultura de Davos» (individualismo, economía de mercado y democracia política), que sólo es compartida por una pequeña élite. 4. Pautas de consumo y de cultura popular occidentales expandidas a través de los medios de comunicación, etc. 
cristiana de la Europa Occidental, y que nunca echará raíces fuera de los confines de esa cultura (Fukuyama, 2006: 16).

Por ello, para Huntington, «la civilización occidental es valiosa, no porque sea universal, sino porque es única», por lo tanto, lo que corresponde no es tratar de remodelar otras civilizaciones a imagen de Occidente, «sino preservar, proteger y renovar las cualidades únicas de la civilización occidental» (Ibidem: 424).

Y lo mismo debe hacer, lógicamente, cada civilización, con lo que el punto de llegada de la posición de Huntington está claro. Cada una de las civilizaciones existentes debe preservar sus propios valores, y todos habremos de reconocer, mantener y potenciar las diferencias esenciales entre las civilizaciones como un hecho inevitable e insuperable. Y en ello además está en juego la propia supervivencia global. «Evitar una guerra mundial entre civilizaciones depende de que los líderes mundiales acepten la naturaleza de la política global, con raíces en múltiples civilizaciones, y cooperen para su mantenimiento» (Ibidem: 21).

Apareciendo, muy especialmente en este punto final, con total nitidez, el planteamiento esencialista referido a las culturas y a las civilizaciones. Por un lado al abordar la cuestión de la decadencia occidental, que no se debe a causas económicas o demográficas, cuanto morales. ${ }^{11} \mathrm{Y}$ sobre todo al incidir en la preservación de una presunta sustancia de la cultura, sin mezclas ni contaminaciones disolventes, hasta el punto de desplazarse aquí el «verdadero choque»:

La cultura occidental está cuestionada por grupos situados dentro de las sociedades occidentales. Uno de esos cuestionamientos procede de los inmigrantes de otras civilizaciones que rechazan la integración y siguen adhiriéndose y propagando los valores, costumbres y culturas de sus sociedades de origen [...]. En Europa, la civilización occidental también podría quedar socavada por el debilitamiento de su componente central, el cristianismo $[\ldots]$.

Los multiculturalistas estadounidenses rechazan igualmente la herencia cultural de su país. Sin embargo, en lugar de intentar identificar a los Estados Unidos con otra civilización, desean crear un país de muchas civilizaciones, lo que equivale a decir un país que no pertenezca a ninguna civilización y carezca de núcleo cultural $[\ldots]$.

El choque entre los multiculturalistas y los defensores de la civilización occidental y del credo estadounidense es, según la frase de James Kurth, «el verdadero choque» dentro del sector americano de la civilización occidental (Ibidem: 414, 416 y 417).

${ }^{11}$ Los problemas de decadencia moral, suicidio cultural y desunión política en Occidente (cuyas manifestaciones son la conducta antisocial, la decadencia familiar, el descenso del «capital social», el debilitamiento de la «ética del trabajo» y el auge de un culto de tolerancia personal) (Ibidem: 413). 
De un plumazo, los complejos problemas de integración cultural y de gestión de la diversidad cultural en el interior de una civilización son reducidos a la pura «asimilación» del diferente, de lo que se hace además un problema de supervivencia para Occidente que depende de esta supuesta reafirmación de su identidad occidental. Pero Huntington no propone la expansión de Occidente por el mundo, el «universalismo imperialista» que rechaza, sino que aceptemos la nueva naturaleza de la política global, con raíces en siete $\mathrm{u}$ ocho civilizaciones y cooperemos a su mantenimiento.

El multiculturalismo dentro del país amenaza a los Estados Unidos y a Occidente; el universalismo fuera de él amenaza a Occidente y al mundo. Ambos niegan la unicidad de la cultura occidental. Los monoculturalistas a escala mundial pretenden hacer el mundo como los Estados Unidos [...]. Un mundo multicultural es inevitable porque un imperio planetario es imposible (Ibidem: 433).

El resultado no puede ser otro que el de una separación radical de las civilizaciones definidas por su particularidad exclusiva que conduce, por lo tanto, a la construcción de sociedades homogéneas en el interior de cada una de ellas. Huntington rechaza el multiculturalismo y el relativismo cultural a nivel micro, en el interior de las civilizaciones, pero es un multiculturalista, o un «multicomunitarista», según la acertada expresión de Touraine, y un relativista cultural-civilizacional convencido a nivel macro, defendiendo que las siete $\mathrm{u}$ ocho civilizaciones existentes permanezcan separadas e incomunicadas entre sí, pues si se mezclan se pierden los valores únicos que ellas representan. ${ }^{12}$ Planteamiento hobbesiano en el fondo y, por ello, contrario a todo tipo de universalismo.

El derecho internacional del orden de grandes espacios traslada el principio de no intervención a las esferas de influencia de grandes potencias que afirman unas contra otras sus culturas y formas de vida, soberanamente y con la fuerza de las armas si es necesario [...]. Pero este diseño carga a estos grandes espacios de connotaciones que lindan con la idea de un «choque de civilizaciones» (Habermas, 2006: 186-187).

Pero en este preciso momento, tras 432 páginas y llegando al final, como si de una novela de misterio se tratase, Huntington da un giro inesperado al

${ }^{12}$ Debe quedar claro, por otro lado, que tal planteamiento es «irreal» y que conlleva una fuerte connotación ideológica, como muy bien señala Touraine, pues hoy en día la mayoría de las sociedades del mundo son de hecho más «multiculturales» que nunca. «El «monoculturalismo» como el «multicomunitarismo», en sus formas extremas (la de una sociedad mundial, o, a la inversa, la de una multiplicidad de universos culturales separados unos de otros y que sólo se comunican entre sí por el mercado) son afirmaciones ideológicas u operaciones políticas más que realidades sociales y culturales» (Touraine, 1997: 227). 
argumento de su libro que desconcierta al lector. Es al introducir la tercera norma de acción de cara a evitar las guerras civilizacionales, la norma de los «atributos comunes», y para ello se apoya en el concepto de moralidad minimalista «tenue» de la moral universal que procede de Michael Walzer. No es una casualidad que se apoye en un comunitarista como Walzer, quien tampoco parece diferenciar convenientemente entre la génesis histórico-social de los valores y la justificación de su validez. Su planteamiento -alejado sin embargo de toda la lógica argumental anterior de Hungtinton- se basa en la búsqueda empírico-inductiva de valores comunes entre las distintas culturas y todo lo más llega a plantear un universalismo ético estrecho concebido como un acuerdo práctico de carácter ocasional y temporal.

La vacuidad del universalismo occidental y la realidad de la diversidad cultural a escala mundial, ¿conducen inevitable e irrevocablemente al relativismo moral y cultural? [...]. «Sí y no. Las culturas son relativas; la moralidad es absoluta $[\ldots]$ por encima de esta moralidad maximalista, superándola y naciendo al mismo tiempo de ella, hay una moralidad minimalista, «tenue», que incorpora «características reiteradas de las moralidades densas o maximalistas particulares». Los conceptos morales mínimos de verdad y justicia se encuentran en todas las moralidades densas y no se pueden separar de ellas. También hay mínimos «mandatos [morales] negativos, muy probablemente normas contra el asesinato, el engaño, la tortura, la opresión y la tiranía» [...]. En lugar de promover las características supuestamente universales de una civilización, los requisitos de la convivencia cultural exigen investigar lo que es común a la mayoría de las civilizaciones. En un mundo de múltiples civilizaciones, la vía constructiva es renunciar al universalismo, aceptar la diversidad y buscar atributos comunes $[\ldots]$.

Los pueblos de todas las civilizaciones deben buscar e intentar ampliar los valores, instituciones y prácticas que tienen en común con los pueblos de otras civilizaciones (Ibidem: 433-434 y 436).

Pero no se entiende, incluso desde tal planteamiento, que, en esa búsqueda o ampliación de valores e instituciones comunes, Huntington desestime los únicos valores existentes realmente universales, que poco a poco van logrando un más amplio consenso, principalmente los derechos humanos y la democracia, y su plasmación institucional, ciertamente precaria e insuficiente, en organizaciones internacionales como las Naciones Unidas, dando por bueno el relativismo cultural que confina su validez a allí donde han emergido históricamente.

En este sentido, poco después de aparecer el libro de Huntington, en la sesión plenaria de la Asamblea General de las Naciones Unidas del día 21 de septiembre de 1998, el Presidente de la República Islámica de Irán, S. M. Khatamí, propuso que se declarase el año 2001 como el «Año del Diálogo entre las Civilizaciones». Días después, el 4 de noviembre, el representante de Irán, al presentar a la Asamblea General el proyecto de resolución, apo- 
yado ya por unos 50 países, se enfrentaba directamente a la tesis del «choque de civilizaciones» y proponía la alternativa del «diálogo entre civilizaciones» como un «paradigma sensato y razonable para abordar los problemas mundiales». El proponente se quejaba de que

... hoy, cuando la comunidad internacional tiene una oportunidad real y única de apartarse de las políticas de dominación y exclusión propias de la guerra fría, se estén proponiendo ideas y teorías para institucionalizar y aun santificar y así perpetuar la mentalidad asociada con las rivalidades y los conflictos del pasado. Esto se hace magnificando el enfrentamiento entre intereses políticos y económicos rivales hasta el nivel de las diferencias irreconciliables entre civilizaciones y del choque inevitable entre ellas. Es evidente que, en víspera del nuevo milenio, el mundo no puede permitirse iniciar un nuevo capítulo de su vida con ideas tan peligrosas, que producen intolerancia y pasan por alto la red siempre creciente de interacción entre las naciones en un mundo cada vez más interdependiente $[\ldots]$.

Habida cuenta del papel fundamental de la cultura en la tarea de forjar las estructuras políticas y económicas, la promoción del diálogo entre distintas culturas, sobre la base de la tolerancia y el respeto de la diversidad, tendría como resultado la reducción de la tensión y contribuiría a la paz y la seguridad internacionales. El diálogo no garantizaría por sí solo la erradicación de los males de la guerra y la intolerancia. No obstante, proporciona un paradigma sensato y razonable para abordar los problemas mundiales que probablemente enfrentaremos en el siglo XXI (N. U., 1998: 2).

En septiembre de 2000, la Asamblea General de las Naciones Unidas aprobaba la Declaración del milenio, importante proclamación donde los Jefes de Estado y de Gobierno de los países miembros ratificaban la validez y universalidad de la institución mundial y de ciertos valores y principios comunes. «Reafirmamos nuestra adhesión a los propósitos y principios de la Carta de las Naciones Unidas, que han demostrado ser intemporales y universales. A decir verdad, su pertinencia y su capacidad como fuente de inspiración han ido en aumento conforme se han multiplicado los vínculos y se ha consolidado la interdependencia entre las naciones y los pueblos» (N. U., 2000).

Al año siguiente, y en pleno «Año de las Naciones Unidas del Diálogo entre las Civilizaciones», el 9 de noviembre de 2001, la Asamblea General, «destacando que todas las civilizaciones están unidas por una humanidad común» y «la necesidad de reconocer y respetar la riqueza de todas las civilizaciones y de buscar un terreno común entre las civilizaciones para hacer frente al conjunto de los problemas comunes de la humanidad», proclamó el «Programa Mundial para el Diálogo entre Civilizaciones», planteándose una serie de objetivos cuya persecución habría de verse «facilitada por la adhesión colectiva a los siguientes principios»: «El cumplimiento de buena fe de las obligaciones establecidas en virtud de la Carta de las Naciones Unidas y 
de la Declaración Universal de Derechos Humanos. El respeto a los principios fundamentales de la justicia y del derecho internacional» (N. U., 2001).

\section{Conclusión: ¿hacia dónde va la «política global»?}

Coincidiendo prácticamente con tan solemne proclamación, los terribles atentados terroristas del 11 de septiembre de 2001, perpetrados en pleno corazón de los EE. UU., alterarían de forma radical el panorama internacional. El gobierno estadounidense presidido por George W. Bush reaccionó con la estrategia de la «guerra contra el terror», instigada por la corriente neoconservadora del equipo de Exteriores, y llevada a cabo por los EE. UU. junto con algunos aliados. ${ }^{13}$ Dentro de tal estrategia se decidió invadir Iraq unilateralmente, ignorando el derecho internacional y marginando a las Naciones Unidas al prescindir de la decisión de su Consejo de Seguridad. ${ }^{14}$

El modelo geoestratégico subyacente a la actuación del gobierno estadounidense, alejado tanto del paradigma del «choque de civilizaciones» como del diálogo entre ellas, es el de la imposición unilateral de un orden mundial unipolar. Pero, como ha escrito Jürgen Habermas, «una potencia que utiliza su superioridad militar, tecnológica y económica para establecer, según sus propios conceptos del bien y el mal cargados de connotaciones religiosas, un orden mundial que sea además conveniente desde el punto de vista geoestratégico» (2006: 144), recae en el falso universalismo de los anti-

${ }^{13}$ Huntington firmará una Carta desde América, junto a unos 60 académicos estadounidenses (Francis Fukuyama, Michael Walzer, Amitai Etzioni o Michael Novak, entre ellos), donde se apoya la «guerra contra el terror» de su gobierno, a la que califican de «guerra justa» y creen no sólo justificada sino incluso exigida moralmente. En dicho texto, tras sostener encontrarse, después de los atentados del 11 de septiembre, «en tiempos de guerra y de crisis global», escriben: «Reconocemos que la Guerra es terrible, representando finalmente la falla de la política humana [...]. No obstante, la razón y la reflexión moral nos enseñan que hay veces en las que la primera y más importante réplica al mal es pararlo. Hay veces en las que embarcarse en una guerra no es sólo moralmente permitido sino moralmente necesario, como una respuesta a calamitosos actos de violencia, odio e injusticia. Ésta es una de esas veces». La guerra, argumentan, es declarada a un movimiento político-religioso violento (del que forma parte la red islamista radical internacional Al Qaeda), movimiento «extremista y radicalmente intolerante que ahora amenaza al mundo, incluyendo al mundo musulmán». Para concluir: «Asesinos organizados con alcance global nos amenazan ahora a todos nosotros. En nombre de la moralidad humana universal, y plenamente conscientes de las restricciones y requerimientos de una guerra justa, apoyamos a nuestro gobierno, y a nuestra sociedad, en su decisión de usar la fuerza de las armas en contra de ellos» (cito por su traducción al castellano señalada en la bibliografía: VV. AA., 2002).

${ }^{14}$ Kepel recuerda que antes del atentado a las Torres Gemelas de Nueva York el principal objetivo de los neoconservadores era la eliminación de Hussein, líder del considerado principal Estado «canalla» de la región y una amenaza para Israel, y que el 11S de 2001 no fue sino la disculpa perfecta para un objetivo ya previsto de antemano (Kepel, 2004: 79-82). 
guos imperios que sostiene que sus propios valores son universales y deben ser aceptados por el resto para su propio bien, lo que no puede ser más opuesto al verdadero universalismo.

Precisamente el núcleo universalista de la democracia y los derechos humanos es lo que prohíbe su imposición unilateral a sangre y fuego. La pretensión de validez universalista que Occidente vincula a sus «valores políticos fundamentales», es decir, al procedimiento de autodeterminación democrática y al vocabulario de los derechos humanos, no debe confundirse con la pretensión imperialista de que la forma de vida política y la cultura de una democracia determinada, aunque sea la más antigua, es ejemplar para todas las sociedades (Ibidem: 40).

Siendo los elementos económico e ideológico, en definitiva, los que siguen actuando como los principales concurrentes en el desencadenamiento y el desarrollo del «nuevo» «choque de civilizaciones» (Martínez, 2002: 82).

El teólogo católico Hans Küng, en una reciente entrevista de prensa, al presentar un libro sobre el islam, aludía a tal estrategia unilateral global que propaga el «choque entre civilizaciones» en lugar de tratar de mitigarlo en la medida de lo posible. Ante la pregunta del periodista, parafraseando la célebre frase del Manifiesto Comunista, « ¿El fantasma que recorre el mundo es ahora el islamismo?», respondía lo siguiente:

Existían de hecho relaciones bastante buenas entre los países occidentales y los países islámicos. Pero se han visto progresivamente envenenadas, por un lado, por el problema del Estado palestino, aplazado desde hace décadas, y por otro, por las nuevas guerras ofensivas, sobre todo de Estados Unidos en Afganistán y en Iraq. Mi libro debe contribuir a dibujar una imagen realista del islam, situada entre su imagen hostil y su imagen ideal, ambas unilaterales. Esto exige de ambas partes la autocrítica, y el esfuerzo por entender las religiones desde su interior. La imagen hostil del islam es sin duda propagada por los neoconservadores americanos. Mucho antes del 11 de septiembre ya forjaban planes para controlar mediante una guerra las fuentes de petróleo en Iraq, para establecer la hegemonía de EE. UU. en Oriente Próximo y, con ella, la seguridad de Israel a costa de los palestinos (Küng, 2006).

La imagen del periodista es, además, adecuada porque permite aludir a una «transferencia» del papel del enemigo por excelencia que se habría producido, de manera planificada, tras el final de la guerra fría.

La evidencia de la existencia de esa grandiosa estrategia es irresistible. En 1991, The Washington Post filtró la noticia de la existencia de un estudio continuo por parte de los departamentos de defensa y espionaje estadounidenses de la necesidad de encontrar un nuevo enemigo común: 
el islam fue el candidato. Muchos de los autorizados diarios de política exterior, semanarios y periódicos han celebrado simposios y publicado artículos y estudios proclamando la amenaza del islam (Said, 1996: 14).

En una de esas revistas de política exterior sería donde Huntington publicaría su artículo planteando su debatida tesis, continúa Said, que en la línea de Bernard Lewis presentaba al islam como incompatible y enemigo de Occidente. Kepel, aludiendo a tal transferencia de enemigos, reiterará las numerosas críticas a la visión monolítica y distorsionada del islam sostenida por Huntington y otros que...

hacen del islam -flanqueado por el confucianismo- el otro por excelencia de Occidente, un otro hostil [...].

... busca sobre todo sustituir un enfrentamiento del Bien y del Mal por otro $[\ldots]$.

En absoluto, el mundo musulmán no es ni monolítico ni homogéneo. Incluye una pluralidad de centros en encarnizada competencia por la hegemonía en los valores político-religiosos. Su relación con Occidente y la modernidad que éste inventa y difunde resulta ser más compleja, profunda e íntima que el tajante antagonismo ideológico y militar que prevalecía entre Estados Unidos y la Unión Soviética [...]. La inesperada aparición de la teoría del choque civilizaciones es un asunto de oportunidad: aparece en el momento idóneo para permitir la transferencia al mundo musulmán de la hostilidad ideológica heredada de décadas de la Guerra Fría (Kepel, 2004: 74 y 75-76).

La política unilateral del gobierno estadounidense, que margina el derecho internacional y está dispuesto a asumir el coste de una ruptura con Europa, ha provocado, a juicio de Habermas, la división de Occidente. El propio Huntington, neoconservador declarado, comparte el desprecio por la insignificante Europa al margen del liderazgo estadounidense. «Si los Estados Unidos se desoccidentalizan, Occidente queda reducido a Europa y a unos pocos países ultramarinos de colonos europeos escasamente poblados. Sin los Estados Unidos, Occidente se convierte en una parte minúscula y decreciente de la población del mundo, en una península pequeña y sin trascendencia» (Huntington, 2005: 417).

Como sostiene Habermas en el prefacio a su libro El Occidente escindido, tras esta escisión está en juego nada menos que uno de los logros civilizatorios más sobresalientes de la humanidad: «Está en juego el proyecto kantiano de suprimir el estado de naturaleza entre los Estados. No son fines políticos superficiales lo que divide a los espíritus, sino uno de los más grandiosos esfuerzos de civilización del género humano» (Habermas, 2006: 9). El mismo Fukuyama nos recuerda, al contraponer su hipótesis del «fin de la historia» a la del «choque de civilizaciones», que frente a los Estados Unidos, que creen que la legitimidad reside exclusivamente en la soberanía esta- 
tal, parte del proyecto europeo moderno consiste precisamente en el intento de superación del Estado nacional.

Estas perspectivas, europea y estadounidense, surgen de sus respectivas historias. Para los europeos, el Estado-nación soberano ha sido una fuente de egoísmo colectivo y de nacionalismo que estuvo en la raíz de las dos guerras mundiales del siglo Xx; el proyecto europeo ha tratado de sustituir la política de poder por un sistema de normas, leyes y organizaciones. Los estadounidenses, por el contrario, han tenido una experiencia más feliz con el uso legítimo de la violencia por parte de su Estado-nación (Fukuyama, 2006: 17).

Ante la gran magnitud de los retos a los que se enfrenta la humanidad, dado el curso actual de la globalización, y entre los cuales la coexistencia entre Occidente y el mundo islámico es una más, singularmente importante, la respuesta no puede ser otra que la de una «globalización ética», una mundialización de la justicia y de la solidaridad apoyada en valores e instituciones realmente universales. Lo mal pasa por la construcción de una ciudadanía política y multicultural, basada en el diálogo, y cuyo último fundamento no puede ser otro que la promoción del desarrollo económico y la lucha en contra de las enormes desigualdades económicas y sociales existentes en el mundo global. Dimensiones fundamentales que Huntington omite en su nuevo paradigma para la política global. En esta dirección, nos recuerda Habermas, es decisiva la forma en que Occidente se presenta normativamente ante el resto de las culturas. Y si quiere ser percibido como una entidad realmente «civilizadora», escribe -y aquí civilización adquiere un significado totalmente distinto al de Huntington, de civilización «en singular», en el sentido de un progreso de orden moral-, deberá cambiar muchos aspectos decisivos de su política global.

Sin una domesticación política del capitalismo sin fronteras no es posible hacer frente a la devastadora estratificación de la sociedad mundial. Debería equilibrarse, como mínimo, la desigual dinámica de desarrollo de la economía mundial en sus consecuencias más destructivas (pienso en la degradación y extensión de la miseria en regiones enteras y en continentes enteros). No se trata sólo de la discriminación, la humillación y el menosprecio de otras culturas. El tema del «choque de civilizaciones» es a menudo el velo tras el que se difuminan los sólidos intereses materiales de Occidente (por ejemplo, el interés de disponer de los yacimientos petrolíferos y asegurar el abastecimiento de energía) (Habermas, 2006: 25).

Es precisamente este tercer modelo, que no persigue la occidentalización del resto de las culturas, una cultura planetaria (ser «iguales»); ni el reforzamiento de culturas estancas que se afirman en la exclusión unas de las otras (ser «diferentes»); sino que se basa en el respeto de las culturas y en el diálogo intercultural, el único que puede responder al interrogante planteado 
por Alain Touraine en su libro: ¿Podremos vivir juntos? Sólo sobre la base de una globalización más justa y solidaria y pugnando por hacer posible «un entendimiento intercultural en torno a interpretaciones de los derechos humanos y la democracia susceptibles de aprobación universal» (Habermas, 2006: 187), podremos vivir juntos, iguales y diferentes a un mismo tiempo.

\section{Bibliografía citada}

Bell, Daniel (1994): «¿Choque de civilizaciones?», El País, 6 agosto, pp. 9 y 10.

FuKUYAMA, Francis (2006): «Después del "fin de la historia". Epílogo a la Segunda edición en rústica de El fin de la historia y el último hombre», El País (Babelia), 18 junio, pp. 16 y 17.

Habermas, Jürgen (2006): El Occidente escindido. Pequeños escritos políti$\cos X$, Madrid: Trotta.

Huntington, Samuel P. (2002/1993): ¿Choque de civilizaciones?, Madrid: Tecnos.

- (2005/1996): El choque de civilizaciones y la reconfiguración del orden mundial, Barcelona: Paidós.

KePEL, Gilles (2004): Fitna. Guerra en el corazón del islam, Barcelona: Paidós.

KüNG, Hans (2006): «Entrevista», El País, 25 junio, pp. 48 y 50.

MARDONES, José María (1998): «Geopolítica y religión: el protagonismo de las religiones en la época de la globalización», Neoliberalismo y religión. La religión en la época de la globalización, Estella: Verbo Divino, pp. 119-146.

MarTínez MonTÁvez, Pedro (2002): «Epílogo crítico», en ¿Choque de civilizaciones?, Tecnos: Madrid, pp. 73-90.

Michel, Patrik (1994): Politique et religion. La grande mutation, París: Albin Michel.

MustafA, Hala (2003): «El islam y occidente en tiempos de globalización: ¿coexistencia o choque de civilizaciones»?, ¿Europa musulmana o euroislam? Política, cultura y ciudadanía en la era de la globalización $(\mathrm{N}$. Alsayyad, y M. Castells, eds.), Madrid, Alianza, pp. 129-151.

NACIONES UnIDAS (1998): 53. a sesión plenaria de la Asamblea General, Nueva York, 4 de noviembre (A/53/PV.53).

- (2000): «Declaración del milenio», Nueva York, 13 de septiembre (A/RES/55/2).

- (2001): «Programa Mundial para el Diálogo entre Civilizaciones», Nueva York, 21 de noviembre (A/RES/56/6).

PNUD (2004): La libertad cultural en el mundo diverso de hoy. Informe sobre desarrollo humano 2004, Programa de las Naciones Unidas para el Desarrollo (PNUD), Madrid: Mundi Prensa. 
Quintanas, Anna (2002): «Una crítica político-antropológica al "choque de civilizaciones" de Samuel P. Huntington», Isegoría, 26, pp. 239-250.

SAID, Edgard W. (1996): «La campaña contra el "terror islámico"», El País, 15 abril, pp. 13 y 14.

- (2001): «El choque de ignorancias», El País, 16 de octubre, pp. 23 y 24.

The Pew Global Project (2006): «The great divide: How westerners and muslims view each other». 13-Nation Pew Global Attitudes Survey (<www.pewglobal.org $>$ ).

TOURAINE, Alain (1997): ¿Podremos vivir juntos? Iguales y diferentes, Madrid: PPC.

URRUTIA, Manuel M. ${ }^{\text {a }}$ (2007): «El "regreso de Dios" a la política: las religiones "públicas"», Estudios de Deusto, vol. 55/1, enero-junio, pp. 243-261.

VV. AA. (2002): «What we're fighting for: a letter from America», Institute for American Values, New York, february (<www.americanvalues.org/ $\mathrm{html} / \mathrm{wwff} . \mathrm{html}>$ ) (existe traducción al castellano en <www.aunmas.com/ ataque/parte_030.htm>). 